Portland State University

PDXScholar

3-1-1999

\title{
Developmental Trajectories of Disruptive Behavior Problems in Preschool Children of Adolescent Mothers
}

\author{
Susan J. Spieker \\ University of Washington \\ Nancy C. Larson \\ Steven M. Lewis \\ Thomas E. Keller \\ Portland State University, kellert@pdx.edu \\ Lewayne D. Gilchrist \\ University of Washington
}

Follow this and additional works at: https://pdxscholar.library.pdx.edu/socwork_fac

Part of the Social Work Commons

Let us know how access to this document benefits you.

\section{Citation Details}

Spieker, Susan J., Nancy C., Larson, Steven M. Lewis, Thomas E. Keller, Lewayne Gilchrist. (1999).

Developmental trajectories of disruptive behavior problems in preschool children of adolescent mothers. Child Development, 70 ( 2 ), 443-458

This Article is brought to you for free and open access. It has been accepted for inclusion in Social Work Faculty Publications and Presentations by an authorized administrator of PDXScholar. Please contact us if we can make this document more accessible: pdxscholar@pdx.edu. 


\title{
WILEY
}

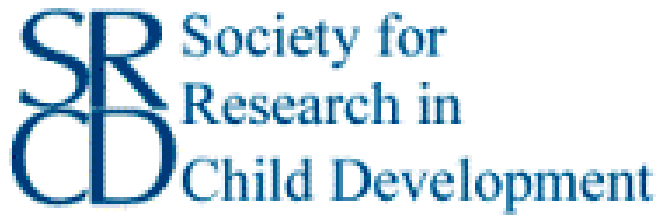

Developmental Trajectories of Disruptive Behavior Problems in Preschool Children of Adolescent Mothers

Author(s): Susan J. Spieker, Nancy C. Larson, Steven M. Lewis, Thomas E. Keller and Lewayne Gilchrist

Source: Child Development, Vol. 70, No. 2 (Mar. - Apr., 1999), pp. 443-458

Published by: Wiley on behalf of the Society for Research in Child Development

Stable URL: http://www.jstor.org/stable/1132099

Accessed: 09/04/2013 19:25

Your use of the JSTOR archive indicates your acceptance of the Terms \& Conditions of Use, available at

http://www.jstor.org/page/info/about/policies/terms.jsp

JSTOR is a not-for-profit service that helps scholars, researchers, and students discover, use, and build upon a wide range of content in a trusted digital archive. We use information technology and tools to increase productivity and facilitate new forms of scholarship. For more information about JSTOR, please contact support@jstor.org.

Wiley and Society for Research in Child Development are collaborating with JSTOR to digitize, preserve and extend access to Child Development. 


\title{
Developmental Trajectories of Disruptive Behavior Problems in Preschool Children of Adolescent Mothers
}

\author{
Susan J. Spieker, Nancy C. Larson, Steven M. Lewis, Thomas E. Keller, and Lewayne Gilchrist
}

\begin{abstract}
Using hierarchical linear modeling (HLM), we analyzed individual developmental trajectories of disruptive behavior problems between ages 3.5 to 6.0 years for 183 children of adolescent mothers. We examined how the level of problem behavior (intercept) and the rate of change over time (slope) are influenced by child's sex, mother's depression/anxiety symptoms, and mother's use of negative control for regulating child behavior. On average, disruptive behavior decreased from age 3.5 to 6.0. Child sex and maternal depression/anxiety related to the level of behavior problems but not to the rate of change. Boys and children of more depressed/ anxious mothers exhibited higher levels of disruptive behavior. Maternal negative control was associated with both level of disruptive behavior and rate of change, and negative control mediated the effects of maternal depression/anxiety. Greater negative control corresponded to higher levels of behavior problems and no reduction in their display over time. Child race moderated effects of negative control.
\end{abstract}

\section{INTRODUCTION}

Defiant, noncompliant, and disruptive behaviors that are problematic in school-age children are developmentally normative in toddlers and preschoolers. About half of children with disruptive behavior problems in the preschool years continue to have disruptive behavior problems in the school years and beyond, but the other half improve (Campbell, 1995). The difficulty is in predicting which children persist. Theoretically, the "early starter" pathway has its roots in infancy, with a progression starting from noncompliance, aggression, and oppositional behavior in the context of parent-child interactions (Patterson, Capaldi, \& Bank, 1991). However, longitudinal studies have a high false-positive rate in identifying preschool-age children who continue on the early-starter pathway (McMahon, 1994).

Three domains of risk factors are implicated in early pathways to disruptive behavior problems: Child risk variables (e.g., child sex, "difficult" temperament), family variables apart from the parentchild relationship (e.g., maternal depression, SES), and parent-child relationship variables (e.g., parent control strategies, negative attitudes) (WebsterStratton, 1996). Greenberg, Speltz, and DeKlyen (1993) call for research charting the trajectories of individuals who vary on these known risk factors for the development of disruptive behavior problems. Whereas traditional longitudinal methods examine stability coefficients, this stability refers only to the rank order of children. Rank order, at any point in time, is independent of whether individual children are on developmental trajectories that are increasing, decreasing, converging, or diverging over time. Particularly in the preschool years, when disruptive behavior is more normative, it is important to know a child's developmental trajectory and the risk factors that are associated with it, to predict the likelihood that problem behavior will accompany the child's entry into school. The study of complex interactions between risk factors is best studied by within participant analyses. Greenberg et al. (1993) recommend the application of analytic techniques such as log-linear analysis and Hierarchical Linear Models (HLM; Bryk \& Raudenbush, $1987 ; 1992)$ to model individual growth trajectories.

Although in nonclinical samples externalizing problems decrease across the preschool years (Campbell, 1995), the children of adolescent mothers may have different trajectories in part because of risk factors associated with their mothers' early childbearing, such as low income, little education, and family disruption (Spieker, Larson, Lewis, White, \& Gilchrist, 1997). This study uses HLM to describe individual trajectories of disruptive behavior problems for 183 preschool children of adolescent mothers, and examines how certain features of the child, the mother, and the mother-child relationship contribute to individual differences in developmental pathways of disruptive behavior.

\section{Sex Differences in Developmental Trajectories}

A variety of studies show clearly that boys are at higher risk than girls for developing externalizing problems. Their greater biological vulnerability is reflected in higher rates of neurodevelopmental disor-

(C) 1999 by the Society for Research in Child Development, Inc. All rights reserved. 0009-3920/99/7002-0013 
ders and attention deficit hyperactivity disorder (ADHD) (American Psychiatric Association, 1994). Boys also experience greater exposure to psychosocial stressors (Eme \& Kavanaugh, 1995). Differences between boys and girls in rates for problem behaviors, however, do not emerge until the preschool years. At ages 2 and 3 behavior problem norms are the same for boys and girls; they diverge beginning at age 4 (Achenbach, 1991a). By school entry, boys exhibit rates of externalizing behaviors up to 10 times the rate noted for girls (Keenan \& Shaw, 1997).

There appears to be less stability in behavior problems overall for girls than for boys (Dishion, French, \& Patterson, 1995), though girls are relatively neglected in studies of developmental pathways (Webster-Stratton, 1996). The somewhat greater plasticity in the behavior problem pathways at younger ages and the complex issues surrounding sex differences in disruptive behavior (Zahn-Waxler, 1993; Zoccolillo, 1993) support the necessity of an intensive longitudinal investigation of very young at-risk boys and girls. However, we are aware of no studies which intensively examine developmental trajectories of externalizing symptoms across the preschool period, when differences between boys and girls begin to emerge. Two aims of the present study are to describe trajectories of disruptive behavior problems for boys and girls during this developmental period, and to determine if child sex moderates the associations of other risk factors with individual trajectories of disruptive behavior problems.

\section{Maternal Depression/Anxiety and Child Disruptive Behavior}

Depressed parents show patterns of uninvolvement and lack of responsiveness (Downey \& Coyne, 1990), hostility and punitiveness toward their children (Ghodsian, Zajicek, \& Wolkind, 1984; WebsterStratton \& Hammond, 1988), and overall parenting skill deficits, compared to nondepressed parents (Teti, Gelfand, Messinger, \& Isabella, 1995). Maternal depression is associated with children's internalizing and externalizing problems (Cummings \& Davies, 1994; Downey \& Coyne, 1990; Gelfand \& Teti, 1990; Zahn-Waxler, Iannotti, Cummings, \& Denham, 1990). Not all studies find depression effects, however. Shaw, Vondra, Hommerding, Keenan, and Dunn (1994) found that maternal depressive symptoms predicted externalizing problems for 3-year-old boys but not girls. When these children were 5, maternal reports of depressive symptoms did not relate to maternal reports of externalizing problems for either sex (Shaw, Owens, Vondra, \& Keenan, 1996). Parental de- pression could also be a response to a child's disruptive behavior. In their review, Dishion et al. (1995) conclude that associations between parental depression and child antisocial behavior are not yet clear with respect to strength or direction of effects.

Symptoms of anxiety and depression frequently co-occur, especially in female adolescents and adults (Compas et al., 1997; Wilhem \& Hadzi-Pavolvic, 1997). In this study we determine if maternal depression/ anxiety is associated with individual children's developmental trajectories of disruptive behavior problems, and whether mothers' depression/anxiety has associations with disruptive behavior problems that differ for boys and girls.

\section{Maternal Negative Control and Child Disruptive Behavior}

There is considerable evidence that mothers' negative control is associated with disruptive behavior problems in their children. Parental verbal negative control tactics (yelling, insulting, threatening) toward children relate to child externalizing symptoms for children of all ages (Vissing, Straus, Gelles, \& Harrop, 1991). In the Vissing et al. study, children who experienced both verbal and physical (slaps, spankings, beatings) control tactics from their parents experienced the highest rates of adjustment problems. Negative control practices, including criticism, yelling, threatening, and physical punishment predicted hardto-manage preschool boys with a diagnosable disruptive behavior disorder at age 9 (Campbell, Pierce, Moore, Marakovitz, \& Newby, 1996). Self-report of corporal punishment as a control strategy at kindergarten entry was associated with acting out behaviors in first grade (Michels, Pianta, \& Reeve, 1993).

There is some empirical support for the hypothesis that the effects of maternal depression/anxiety on child disruptive behavior problems are mediated in part by the poor behavior management skills associated with depression/anxiety and other indicators of family stress, particularly for families with preschoolage children (Miller, Cowan, Cowan, Hetherington, \& Clingempeel, 1993) and families from socioeconomically disadvantaged backgrounds (Dodge, Pettit, \& Bates, 1994; Dumas \& Wekerle, 1995). Campbell et al. (1996) tested this mediational model for mothers of hard-to-manage boys at age 4, using regression analyses according to the three steps outlined by Baron and Kenny (1986). In the first step they found that family stress (a composite of negative life events, marital dissatisfaction, and maternal depressive symptoms) accounted for $17 \%$ of the variance in negative maternal control. In the second step, they found 
that the same family block accounted for $14 \%$ of the variance in a composite of child externalizing ratings. In the third step, they found that when both family stress and negative maternal control were in the regression model predicting to child externalizing ratings, the total variance accounted for was $22 \%$, and the variance accounted for by family stress was reduced to $5 \%$. The evidence for mediation was the finding that, in the third step, maternal negative control attenuated the relation between family stress and child externalizing ratings.

In this study we determine whether maternal negative control is associated with the level of preschoolage children's disruptive behavior problems, as well as with the rate and direction of change in disruptive behavior problems between 3.5 and 6.0 years, the age at which many children begin school. In addition, we follow the same reasoning set forth by Baron and Kenny (1986) and illustrated by Campbell et al. (1996) to test the hypothesis that the effects of maternal depression/anxiety on child disruptive behavior problems is mediated to some extent by maternal negative control, using a different method of analysis, HLM.

\section{Does Cultural Group Moderate the Effects of Negative Control?}

There is an ongoing debate regarding the extent to which the effect of physical discipline is moderated by the severity of the discipline, the cultural group in which the discipline occurs, the parent-child relationship context, and the sex of the parent and child. Deater-Deckard and Dodge (1997) hypothesize that for harsh but not abusive discipline, variations in physical discipline will have less impact on child behavior outcomes for Black families than for White families. They suggest that the differences across cultural groups can be partially explained by variations in the warmth of the parent-child relationship, and the meaning attached to various control strategies. In the present study we test the Deater-Deckard and Dodge hypothesis by examining the interaction between maternal negative control and child race on the absolute level of disruptive behavior problems and their change over time, for the Black and White children in this sample.

Deater-Deckard and Dodge further hypothesize that the effect of harsh discipline will be stronger when parent and child are of the same sex. The nature of the effect, however, may vary depending on the age of the children and whether the level of behavior problems or change over time is the dependent variable. McFadyen-Ketchum, Bates, Dodge, and Pettit (1996) report empirical data to support this hypothe- sis. They found that mother-child coercion prior to kindergarten predicted initial levels of aggressivedisruptive behavior in kindergarten for both boys and girls, but different growth trajectories over time. Mother-son coercion was associated with increases in sons' aggression, but mother-daughter coercion was associated with decreases in daughters' aggression. It would be interesting if a similar moderating effect was found for even younger children. In the present study we test whether child sex moderates an association between maternal negative control and individual trajectories of preschoolers' disruptive behavior problems.

In summary, this study has four aims. First, we use HLM to describe individual disruptive behavior trajectories across a $2 \frac{1}{2} 2$-year span ( 3.5 to 6.0 years) for a sample of preschool-age children who are at risk for problem behavior because of family factors such as low income, low education, and partner instability, that are known to be associated with their mothers' early childbearing (Spieker et al., 1997). Second, we examine the contribution of risk variables from the child, family, and mother-child domains to children's disruptive behavior problem trajectories. Specifically, we assess the extent to which individual variability can be explained by the child's sex, maternal depression/anxiety symptoms, and maternal negative control of the child during mother/child conflict. Third, we assess the interaction of child sex with maternal depression/anxiety and negative control in the prediction of disruptive behavior problem trajectories for all children, and the interaction of child race with maternal negative control for those children who are of either European American or African American descent. Finally, because all of the variables in the major analyses in this study are derived from maternal report, and common method variance is a well recognized limitation to the generalizability of research findings, we conduct an additional analysis to provide some validation of the trajectories of disruptive behavior problems based on mothers' reports. We use hierarchical regression to predict teacher report of externalizing problems on the Teacher Report Form (TRF; Achenbach, 1991b) at age 6.0 using individual disruptive behavior problem scores at 3.5 and rate of change, or slope of disruptive behavior problems from age 3.5 to 6.0 .

\section{METHOD}

\section{Participants and Procedures}

Unmarried pregnant adolescents, age 17 and younger, who planned to carry their pregnancies to term, were recruited from urban prenatal clinics, al- 
ternative school programs, and social services agencies, for participation in a natural history longitudinal study of adolescent pregnancy and parenting (Gilchrist, Gillmore, \& Lohr, 1990). Because recruitment procedures included advertising, a conventional overall response rate could not be calculated. However, in one agency where recruitment procedures allowed collection of complete approach and consent data, $75 \%$ of eligible adolescents consented to participation. A total of 241 school-age mothers were enrolled in the study and completed the initial interview. Respondents were interviewed 10 additional times within the time frame of 1-month to 6-years postpartum. Retention in the study was high; only one participant refused to continue participation and the failure to locate participants at each time point averaged $2 \%-4 \%$ of the sample.

Overall, study participants at enrollment were similar to the national profile of adolescents who carry their premarital pregnancies to term in that they came from lower socioeconomic backgrounds (35\% of their parents had received welfare in the last year), the majority (93\%) planned to parent their children, and two thirds $(67 \%)$ had either dropped out of school or attended school sporadically. Because the sample was not selected only from alternative schools or special programs serving teens, it represents a broader range of adolescent mothers than is depicted in many published studies.

Compared with 1988 national data of births to adolescents age 17 and under (Charles Stewart Mott Foundation, 1991), the present study sample had slightly fewer Whites (51\% versus $59 \%$ ), somewhat fewer Blacks ( $28 \%$ versus $37 \%$ ), and more in the other categories of race and ethnicity ( $21 \%$ versus $3 \%)$, reflecting this region's demographic profile. In fact, the study sample very closely approximates the ethnic and racial breakdown of adolescents who gave birth in the study area (Seattle-King County Department of Public Health, 1996). Table 1 compares the race and ethnicity of the whole sample with the 183 cases included in the current analysis. There were no significant differences on any variable between those who were included in the present study, and those who were not for reasons listed below.

The current analyses address outcomes for children in the original sample who have been parented continuously or nearly continuously by their biological mothers through age 6. Cases in the original sample of 241 who are not represented in the current study include two mothers who had late-term miscarriages, two whose children died, 15 who placed their children for adoption shortly after birth, one with known false report, one with severe child development delays, and those cases missing child out-
Table 1 Demographic Characteristics of Present and Original Sample of Adolescent Mothers

\begin{tabular}{cccc}
\hline $\begin{array}{c}\text { Present } \\
\text { Sample } \\
(n=183)\end{array}$ & & $\begin{array}{c}\text { Original } \\
\text { Sample } \\
(n=241)\end{array}$ \\
\cline { 2 - 3 } & $\frac{1}{n}$ & $\%$ \\
\hline
\end{tabular}

\begin{tabular}{|c|c|c|c|c|}
\hline \multicolumn{5}{|l|}{$\begin{array}{l}\text { Maternal age during } \\
\text { pregnancy }\end{array}$} \\
\hline Mean age & \multicolumn{2}{|c|}{16} & \multicolumn{2}{|c|}{16} \\
\hline Standard deviation & \multicolumn{2}{|c|}{.99} & \multicolumn{2}{|c|}{1.00} \\
\hline Range & \multicolumn{2}{|c|}{$13-18$} & \multicolumn{2}{|c|}{$12-18$} \\
\hline \multicolumn{5}{|l|}{ Child race/ethnicity } \\
\hline White & 69 & 37.7 & 82 & 34.0 \\
\hline Black & 60 & 32.8 & 70 & 29.0 \\
\hline Black/White & 14 & 7.7 & 14 & 5.8 \\
\hline American Indian & 9 & 4.9 & 11 & 4.6 \\
\hline Asian & 7 & 3.8 & 10 & 4.1 \\
\hline Hispanic & 9 & 4.9 & 12 & 5.0 \\
\hline Other & 13 & 7.1 & 15 & 6.2 \\
\hline Missing & 2 & 1.1 & 27 & 11.2 \\
\hline \multicolumn{5}{|l|}{ Education completed by } \\
\hline \multicolumn{5}{|l|}{3.5 years postpartum } \\
\hline \multicolumn{5}{|l|}{ Less than high school } \\
\hline diploma & 72 & 39.3 & 97 & 40.2 \\
\hline HS diploma/GED & 49 & 26.8 & 58 & 24.1 \\
\hline \multicolumn{5}{|l|}{ Technical/vocational } \\
\hline school & 26 & 14.2 & 34 & 14.1 \\
\hline Some 2 year college & 28 & 15.3 & 33 & 13.7 \\
\hline 2 year college graduate & 3 & 1.6 & 3 & 1.2 \\
\hline Some 4 year college & 3 & 1.6 & 4 & 1.7 \\
\hline Missing & 2 & 1.1 & 12 & 5.0 \\
\hline \multicolumn{5}{|l|}{$\begin{array}{l}\text { Primary source of financial } \\
\text { support } 3.5 \text { years } \\
\text { postpartum }\end{array}$} \\
\hline Public assistance & 122 & 66.7 & 145 & 60.2 \\
\hline Employment & 29 & 15.8 & 39 & 16.2 \\
\hline Boyfriend/husband & 22 & 12.0 & 31 & 12.9 \\
\hline \multicolumn{5}{|l|}{ Parents/other } \\
\hline relatives & 4 & 2.1 & 6 & 2.5 \\
\hline Other & 3 & 1.6 & 8 & 3.3 \\
\hline Missing & 3 & 1.6 & 12 & 5.0 \\
\hline \multicolumn{5}{|l|}{ Child sex } \\
\hline Boys & 109 & 59.6 & 130 & 53.9 \\
\hline Girls & 74 & 40.4 & 91 & 37.8 \\
\hline Unknown $^{\mathrm{a}}$ & & & 20 & 8.3 \\
\hline
\end{tabular}

a Sex of child unknown due to miscarriage, baby death, adoptions.

come data at all six of the time points included in this analysis. The majority of those cases with missing child outcome data were mothers not currently parenting the study child. The time period covered in this analysis is from age 3.5 to age 6.0 of the study child.

\section{Measures}

Disruptive behavior problems. Maternal report on the Behavior Problems Index (BPI; Baker \& Mott, 1989) 
was used as a measure of disruptive behavior problems in children at 6-month intervals between 3.5 and 6.0 years. The BPI was developed by drawing on work by Achenbach and Edelbrock (1981) and earlier child behavior scales. All items used to assess disruptive behavior problems in the present study are also items in the Externalizing broad band scale of the Child Behavior Checklist (Achenbach, 1991a). At age 6.0, the CBCL was administered instead of the BPI, and the items that were also on the BPI were extracted to create the BPI score for that age. The BPI has been used in large, national studies such as the National Longitudinal Survey of Youth (Baker, Keck, Mott, \& Quinlan, 1993).

The mother reported whether each BPI item was never true, sometimes true, or often true for her child. Summary scores for each child at each of the six timepoints were computed from the raw data on 10 items measuring disruptive behavior problems. Sample scale items include: has sudden changes in mood or feeling; argues too much; is stubborn, sullen, or irritable; demands a lot of attention. The mean scores for the BPI disruptive behavior scale ranged from $7.09(S D=4.07)$ to $7.88(4.06)$ over the six timepoints, range $=0-20$. The alpha coefficients varied from .79 to .87 .

The Child Behavior Checklist (CBCL; Achenbach, 1991a) is a widely used, nationally normed, parent rating scale of child psychopathology for children from 4 through 18 years. The CBCL scales are primarily empirically derived. The Externalizing broad band scale is comprised of the Aggressive and Delinquent narrow band scales. The CBCL was administered only at age 6.0. The mean CBCL Externalizing T-score was $56.6(S D=10.6)$, range $=30-88$. Achenbach $(1991 \mathrm{a})$ recommends that the bottom of the clinical range for the CBCL Externalizing scale be $T=60$ (84th percentile). Using that criterion, $33 \%$ of this sample scored in the borderline clinical range on the CBCL.

The Teacher Report Form (TRF; Achenbach, 1991b) is part of an extensive system of scales that includes the CBCL. The developers of these instruments emphasize scales that are common across raters to permit cross-scale comparisons. Item content is analogous for boys and girls. This version and earlier, closely related versions of the TRF have been used extensively, and there is much evidence that the TRF is valid in terms of its ability to differentiate clinic and nonclinic samples, its correlation with observed classroom behavior, and its correlation with independent clinical ratings. The TRF was collected only at age 6.0 years $(n=151)$, and provides some validation of the mothers' reports of disruptive behavior problems. The mean TRF Externalizing $T$-score was 56.2 ( $S D=$
11.0), range $=39-92$. Achenbach (1991b) recommends that the bottom of the clinical range for the TRF Externalizing scale be $T=60$ (84th percentile). Using that criterion, $36 \%$ of this sample scored in the borderline clinical range on the TRF.

Maternal depression/anxiety symptoms. Maternal depression/anxiety during the preschool years was represented by a mean score incorporating measures at six time points from 3.5 to 6.0 years postpartum. Raw scores from the Depression and Anxiety subscales of the SCL-90-R (Derogatis, 1994) were used because of the strong relation between anxiety and depression in women (Compas et al., 1997; Wilhem \& HadziPavlovic, 1997). The depression subscale has 13 items, and the anxiety subscale has 10 items. Mothers reported on their symptoms during the past week. The response choices for each item are on a 5-point scale $(0-4)$, and the total score is the average rating across all items. Alpha coefficients for this combined measure of depression/anxiety were strong at each time point, ranging from .91 to .95 . Intercorrelations among the six time-points ranged from .50 to .75 . The slope for maternal depression/anxiety symptoms across the six time-points indicated that, on averaged, symptom levels did not change significantly over time, $\beta=$ $-.004, p=.81$.

The mean depression/anxiety symptom score was $.69(S D=.49)$, range $=.01-2.52$. Applying the combined nonpatient female norms for these two subscales of the SCL-90-R, $15.3 \%$ of the mothers in the sample were above the 90 th percentile (cutoff $=1.01$ ) for depression/anxiety symptoms at three or more time points. The distribution of the grand mean maternal depression/anxiety scores was positively skewed. A square-root transformation was completed, significantly improving the distribution of this variable, and meeting HLM assumptions for normality. The transformed variable was used in all analyses.

Maternal negative control. The Conflict Tactics Scale (Straus, 1974) with the language changed to designate that the child, rather than spouse, was the interactive partner, was used as a measure of negative control strategies that included both verbal and physical tactics. This measure was collected at two time points, ages 5.5 and 6.0. The scale consists of 11 items, including: yelled, insulted, or swore at your child; threw, smashed, or kicked something; threw something at your child; pushed, grabbed or shoved your child; spanked your child with something. Each item was measured on a 7-point scale ranging from never to nearly every day, and mothers reported on their behavior for the past 6 months. The alpha coefficients were .79 and .74 , the correlation between the two time-points was .63, and there was no difference in 
the means at the two-time points $t(178)=.94, p=$ .35. The mean for the two time-points combined was $11.87(S D=7.25)$, range $=0-34$. This variable was normally distributed.

\section{RESULTS}

\section{Descriptive Analyses}

Correlations between the independent variables and the dependent variable at each of the six timepoints are found in Table 2. Significant correlations were found between all variables. Correlations between the CBCL and TRF Externalizing raw scores and the independent variables and the BPI scores from age 3.5 to 6.0 , are also listed in Table 2. As would be expected, the maternal report measures were highly correlated with each other. The TRF scores were significantly correlated with the BPI scores at four of the six time-points. The TRF was not associated with mothers' depression/anxiety symptoms, and only marginally related to maternal negative control.

\section{Data Analysis}

Hierarchical linear modeling (HLM) is one of several recent multilevel modeling approaches developed to handle the repeated-measures found in longitudinal designs, as well as other nested data. The software program WHLM (Bryk, Raudenbush, \& Congdon, 1994) was selected for the present study due to its ease of use. Analysis of longitudinal data must take into account the lack of indepen- dence between the repeated observations of each person. HLM handles this by specifying both withinparticipants and between-participants equations. Within-participants variables are modeled as "Level1"; between-participants variables are modeled as "Level-2."

A first step in longitudinal analysis is to construct a variable to account for the "time" component of the model. As each of the six assessment points in the present study was 6 months apart, assigning a categorical code for the time variable was sufficient. The first time point was coded as -5 , second as -4 , and so on, with the final time-point being given a value of 0 . This method of coding allowed the final time-point (age 6.0) to be the intercept in the estimated models. In HLM, selection of the intercept is based on theoretical or practical concerns. We chose 6.0 years to be the intercept because of our interest in the children's status at the time of school entry. Time was the only variable modeled at Level-1 in this analysis. Child sex, maternal depression/anxiety symptoms, and negative control were all modeled at Level-2 as between-participants variables. Such variables signify differences between participants and are treated as unchanging over the course of the time period under study.

\section{Growth Curve Analysis}

Unconditional model. The analysis begins by describing the developmental trajectory of disruptive behavior problems across the six assessments completed between age 3.5 and 6.0. The developmental trajectory is composed of an intercept (estimated score at

Table 2 Descriptive Statistics and Correlations Between Maternal Depression/Anxiety Symptoms, Negative Control, BPI Disruptive Behavior Problem Scores 3.5 to 6.0 Years, and CBCL and TRF Externalizing Raw Scores at 6.0 Years

\begin{tabular}{|c|c|c|c|c|c|c|c|c|}
\hline & $\begin{array}{c}\text { Depression/ } \\
\text { Anxiety }\end{array}$ & $\begin{array}{c}\text { Negative } \\
\text { Control }\end{array}$ & $\begin{array}{c}3.5 \\
\text { Years }\end{array}$ & $\begin{array}{l}4.0 \\
\text { Years }\end{array}$ & $\begin{array}{l}4.5 \\
\text { Years }\end{array}$ & $\begin{array}{c}5.0 \\
\text { Years }\end{array}$ & $\begin{array}{c}5.5 \\
\text { Years }\end{array}$ & $\begin{array}{c}6.0 \\
\text { Years }\end{array}$ \\
\hline$n$ & 183 & 183 & 176 & 179 & 174 & 175 & 180 & 182 \\
\hline$M$ & .69 & 11.87 & 7.88 & 7.60 & 7.39 & 7.13 & 7.09 & 7.19 \\
\hline$S D$ & .49 & 7.25 & 4.06 & 3.92 & 3.97 & 3.79 & 4.07 & 4.35 \\
\hline Depression/Anxiety & & $.31^{* * *}$ & $.29^{* * *}$ & $.33^{* * *}$ & $.47^{* * *}$ & $.34^{* * *}$ & $.41^{* * *}$ & $.41^{* * *}$ \\
\hline Negative control & & & $.32^{* * *}$ & $.45^{* * *}$ & $.42^{* * *}$ & $.44^{* * *}$ & $.50^{* * *}$ & $.50^{* * *}$ \\
\hline BPI 3.5 years & & & & $.66^{* * *}$ & $.58^{* * *}$ & $.54^{* * *}$ & $.58^{* * *}$ & $.55^{* * *}$ \\
\hline BPI 4.0 years & & & & & $.73^{* * *}$ & $.69^{* * *}$ & $.74^{* * *}$ & $.68^{* * *}$ \\
\hline BPI 4.5 years & & & & & & $.69^{* * *}$ & $.72^{* * *}$ & $.66^{* * *}$ \\
\hline BPI 5.0 years & & & & & & & $.72^{* * *}$ & $.67^{* * *}$ \\
\hline BPI 5.5 years & & & & & & & & $.77^{* * *}$ \\
\hline TRF 6.0 years & -.00 & $.15^{+}$ & .10 & $.29^{* * *}$ & .12 & $.25^{* *}$ & $.34^{* * *}$ & $.27^{* * *}$ \\
\hline
\end{tabular}

${ }^{+} p<.10 ;{ }^{*} p<.05 ;{ }^{* *} p<.01 ;{ }^{* * *} p<.001$. 
age 6.0) and slope (estimated rate of change over all the assessments). Equations representing this depiction of the developmental trajectory are as follows:

\section{Level-1 model}

$Y($ disruptive behavior problems $)=\pi_{0}+\pi_{1}($ time $)+e$

$$
\begin{array}{ll}
\text { Level-2 model } & \pi_{0}=\beta_{00}+r_{0} \\
& \pi_{1}=\beta_{10}+r_{1}
\end{array}
$$

This unconditional model provides an indication of the average level of behavior problems for children at age 6.0, the average rate of change during the preschool years, and the amount of individual variability in both of these estimates. The estimate of the intercept, or average report of disruptive behavior problems at age 6.0, was 6.97. The average slope, or semiannual rate at which behavior problems changed, showed a significant decreasing slope over the six time-points, $\beta=-.149, p=.004$. The mean developmental trajectory, therefore, decreased at a rate of 149 points every 6 months during the preschool years to an estimated mean of 6.97 at age 6.0.

In the unconditional model there is significant variation around the intercept, $\chi^{2}(182)=1174.74, p<$ .001 , and the slope, $\chi^{2}(182)=313.39, p<.001$, yet to be explained. These results suggest that individual children vary significantly in disruptive behavior problem scores at age 6.0, as well as in their rate of change in scores across the preschool years. Modeling both parameters is necessary to understand the developmental trajectories of disruptive behavior problems in children.

The ratio of parameter variance to the total observed variance provides an indication of "true" variability due to individual differences rather than measurement error (Bryk \& Raudenbush, 1992, p. 40). These ratios for the intercept and slope of disruptive behavior problems in the unconditional model were .84 and .42 . Modeling each parameter further as a function of person-level variables is clearly warranted.

Model 1: Disruptive behavior and child sex. The first person-level, or Level-2, variable to be assessed in relation to developmental trajectories of disruptive behavior problems was sex of the child. As seen in Table 3 , a significant difference in the intercept by child sex was found. As might be expected based on previous literature, the intercept for disruptive behavior problems in boys, 7.63 , was higher within this sample than the intercept for girls, 6.01. No significant difference in the rate of change of disruptive behavior problems by child sex was found for the 2.5 year span of this study. Although not significantly different, the values in the declining slopes for girls and boys hinted at a trend. The computed coefficient was -.22 for girls, compared to -.10 for boys. Further support for the possibility that girls and boys are on gradually diverging trajectories that would require a longer time period to detect is the finding that the simple mean BPI scores for girls and boys were significantly different at every time-point except at age $3.5, M=7.5$ $(S D=3.7)$ for girls versus $M=8.2(S D=4.3)$ for boys, $t(174)=-1.2, p=.25$.

Again, the variance component of the random effects showed significant individual differences in both intercept and slope parameters yet to be explained. By comparing the variance estimates of Model 1 with those in the unconditional model, we computed an index of the proportion reduction in variance, or, loosely speaking, the variance explained by the Level-2 predictors (Bryk \& Raudenbush, 1992, p. 65). This index, which was computed for both the intercept and slope, is listed under "PV" in Table 3. The proportion of variance in the intercept explained by child sex was .039, and the proportion of variance in the slope explained by child sex was .006 . Figure 1 illustrates the trajectories of disruptive behavior problems based on the mean value for boys, girls, and the whole sample.

Models 2-3: Adding maternal depression/anxiety symptoms or negative control. Two separate models were tested to assess the relations between maternal depression/anxiety symptoms and disruptive behavior problems, and between maternal negative control and disruptive behavior problems, accounting for the effect of child sex. The Level-2 equation was expanded to determine whether the developmental trajectory varied by maternal depression/anxiety symptoms or negative control, in turn. Results of these analyses can be found in Table 3 .

Children whose mothers reported more depression/anxiety symptoms had significantly higher disruptive behavior problem scores at age 6.0, but no significant difference in the rate of change of problem behaviors (see Model 2 in Table 3). When depression/ anxiety was added to the model, child sex unexpectedly no longer had a significant effect on the intercept, and the proportion of variance explained (PV) increased from .039 to .229 . According to methods described by Baron and Kenny (1986), these results indicate that some of the effect of child sex is mediated by maternal depression/anxiety symptoms. To explore this finding further we examined mean differences by child sex and found that depression/anxiety symptoms, averaged across the six time-points, were higher for mothers of boys, $M=.82(S D=.27)$, than for mothers of girls, $M=.71(S D=.32), t(181)=-2.39$, $p=.02$. Figure 2 illustrates trajectories of disruptive 


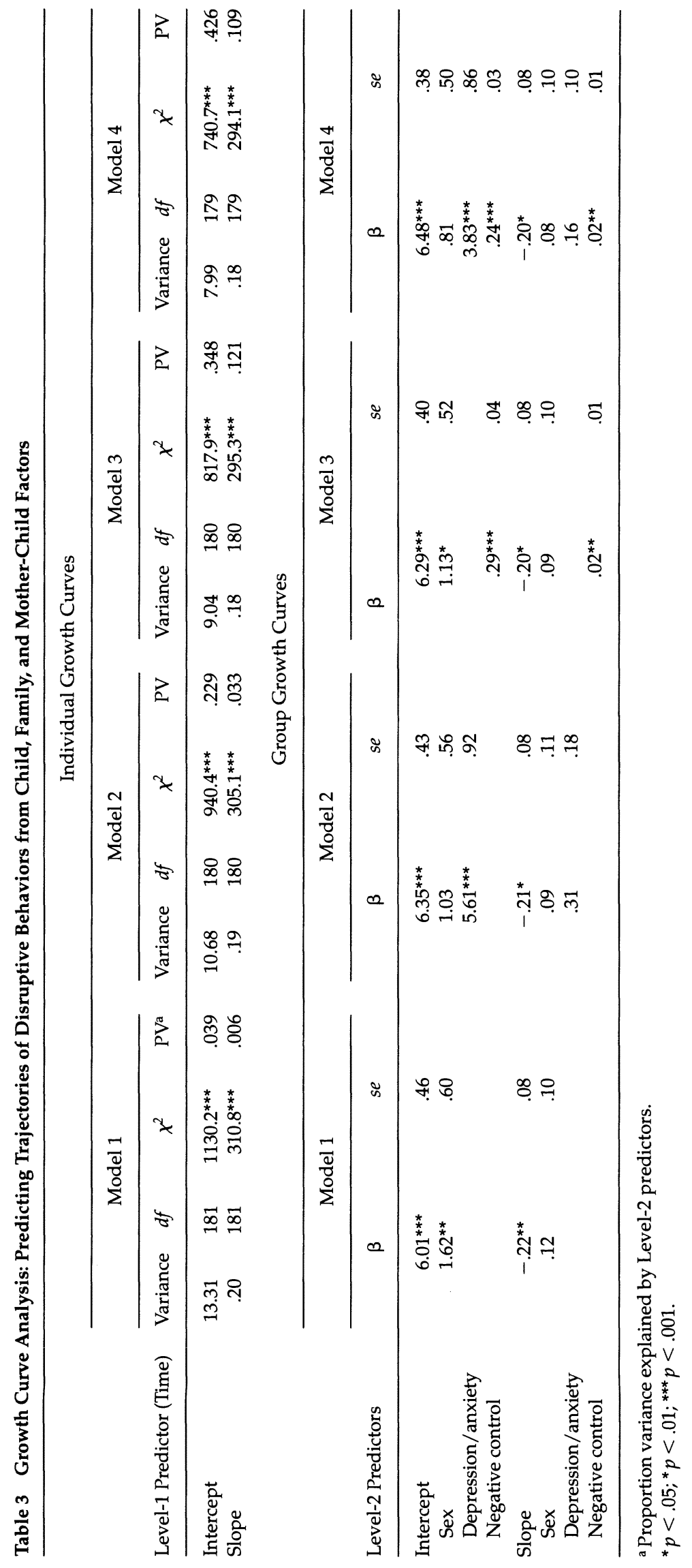




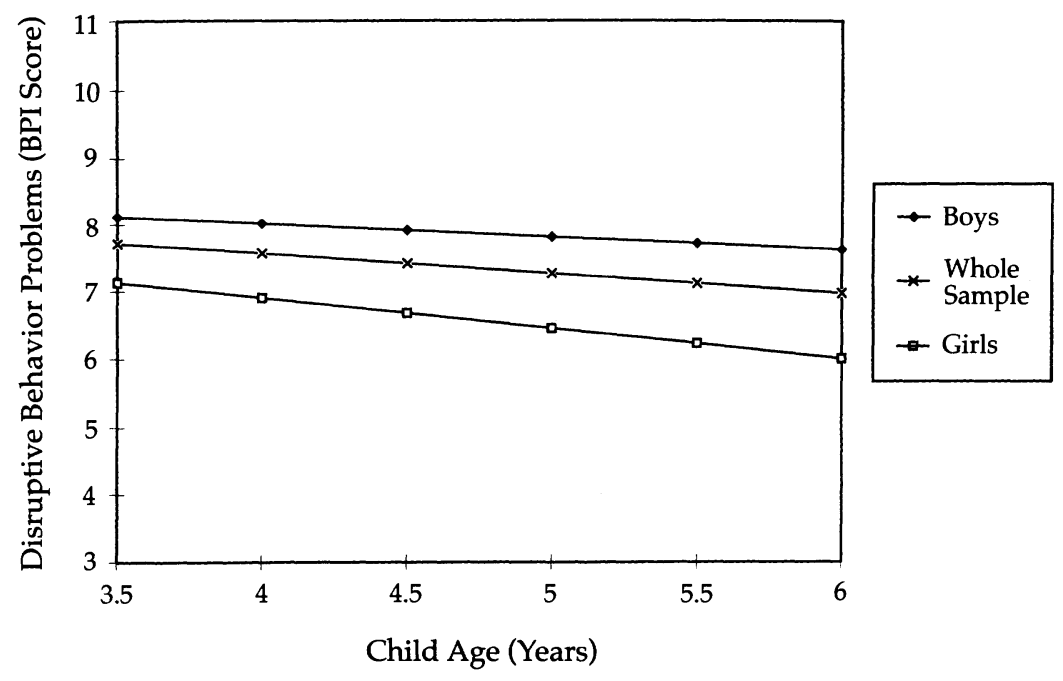

Figure 1 Trajectories of disruptive behavior problems based on the mean values for each grouping.

behavior problems based on maternal depression/ anxiety symptoms that are $1 S D$ above or below the sample mean, for boys and girls.

Children whose mothers reported the use of negative control strategies had significantly higher disruptive behavior problem scores at age 6.0, accounting for the effect of child sex (see Model 3 in Table 3). These children also had a significant difference in the rate of change of disruptive problem behaviors. Both parameters representing the developmental trajectory of disruptive behavior problems increase with increased use of negative control practices. Child sex continued to have a significant, though somewhat reduced, independent effect on the intercept when neg- ative control was entered into the model. The proportion of variance in the intercept explained by child sex and maternal negative control was .348, and the proportion of variance explained in the slope was .121. Figure 3 illustrates trajectories for disruptive behavior problems based on maternal negative control scores $1 S D$ above or below the sample mean.

Model 4: Combining predictors. Thus far, analyses revealed significant effects of child sex, maternal depression/anxiety symptoms, and negative control on the level of disruptive behavior problems when tested in separate models. Only negative control had an independent effect on the rate of change in disruptive behavior problems. A final model incorporating

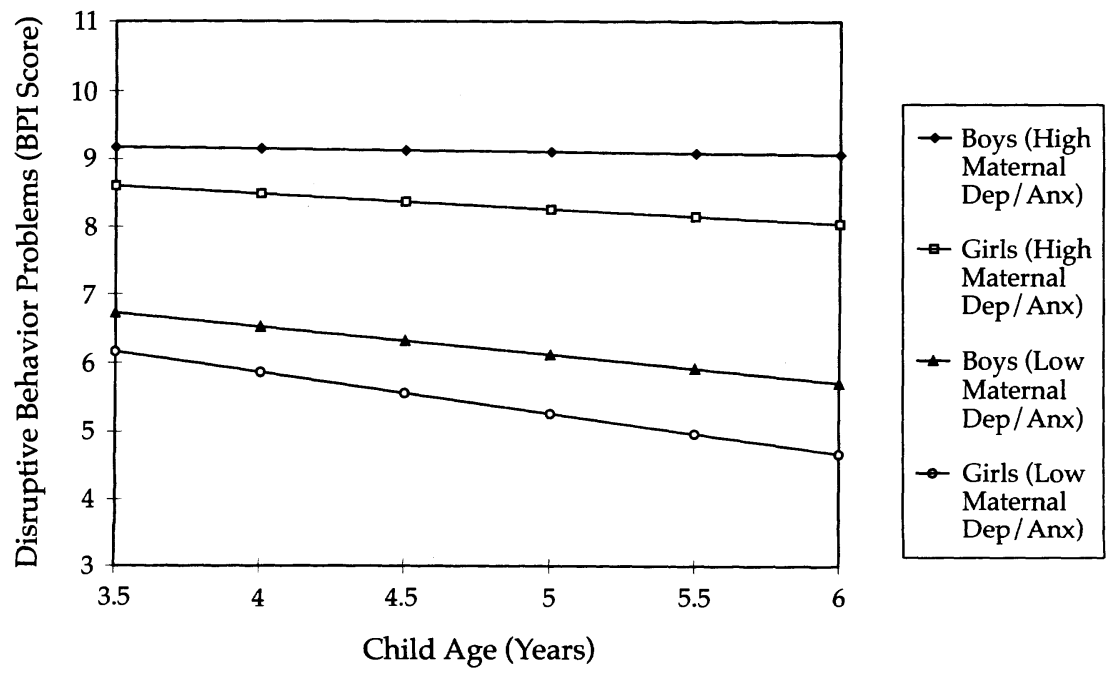

Figure 2 Trajectories of disruptive behavior problems based on maternal depression/anxiety symptoms 1 SD above or below the sample mean. 


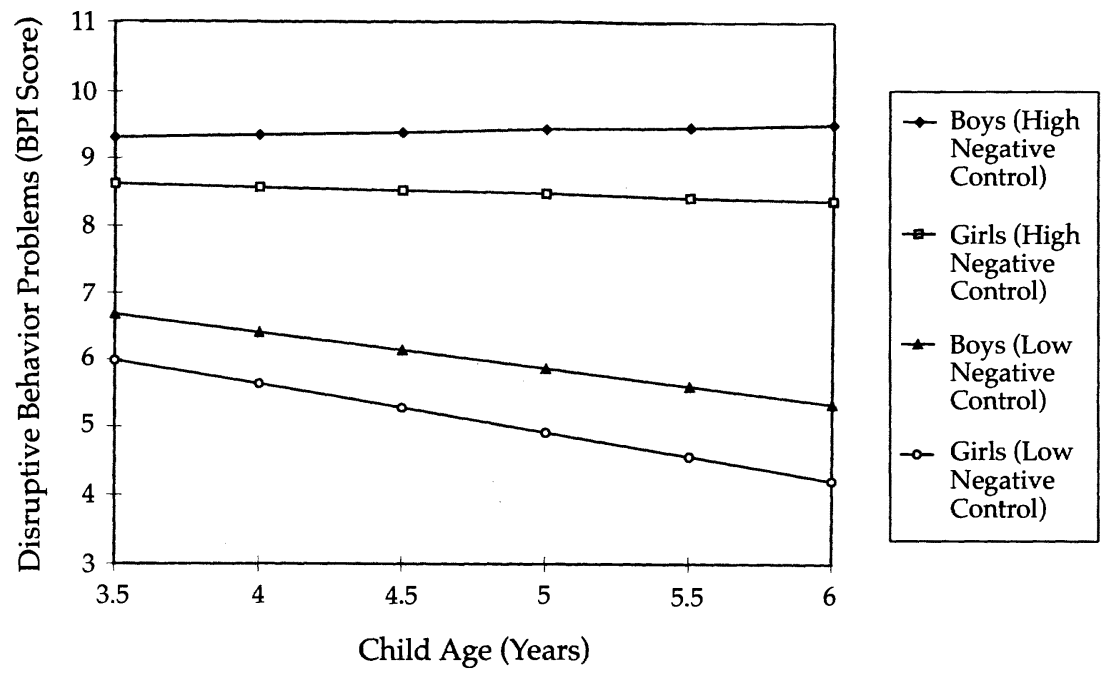

Figure 3 Trajectories of disruptive behavior problems based on maternal negative control $1 S D$ above or below the sample mean.

all three Level-2 predictors was tested. The Level-1 equation for this model remained the same as in the unconditional model. The Level- 2 equations were expanded as follows:

$$
\begin{gathered}
\pi_{0}=\beta_{00}+\beta_{01}(\text { Sex })+\beta_{02}(\text { Depression } / \text { Anxiety })+ \\
\beta_{03}(\text { Negative Control })+r_{0} \\
\pi_{1}=\beta_{10}+\beta_{11}(\text { Sex })+\beta_{12}(\text { Depression } / \text { Anxiety })+ \\
\beta_{13}(\text { Negative Control })+r_{1}
\end{gathered}
$$

This model (Model 4 in Table 3) allows for a test of each main effect when every other effect (with the exception of child sex) is at the grand mean. Tests for mediation will be met if parameter estimates for certain variables in the model decrease relative to earlier models whereas the overall fit (proportion of variance explained) of Model 4 improves (Baron \& Kenny, 1986). Maternal depression/anxiety symptoms and negative control continue to have a significant association with the intercept, the level of disruptive behavior problems at age 6.0. Increases in either of these factors are significantly related to increased levels of disruptive behavior problems. Child sex, however, does not have an independent association with the intercept. The parameter estimate for child sex decreases from 1.62 in Model 1 to .81 in Model 4. This result indicates that the effects of child sex are mediated by maternal depression/anxiety symptoms, as first found in Model 2, and perhaps to some extent also by maternal negative control, because the parameter estimate for child sex also decreased in Model 3. Only negative control has a significant relation with the rate of change in reported disruptive behaviors. The proportion of variance explained with the combined pre- dictors in the model increases to .426 for the intercept, and decreases somewhat to .109 for the slope. The intercept parameter estimate for depression/anxiety symptoms decreases from 5.61 in Model 2 to 3.83 in Model 4 whereas the proportion of variance explained for the intercept increases from .229 in Model 2 to .426 in Model 4, a result which indicates that the effect of maternal depression/anxiety symptoms on the level of child disruptive behavior problems is mediated to some extent by maternal negative control. Figure 4 depicts trajectories of disruptive behavior problems based on combinations of maternal depression/anxiety and maternal negative control, when each variable is either $1 S D$ above or below the sample mean. When mothers report more depression/ anxiety symptoms and more negative control, both boys and girls maintain high levels of disruptive behaviors. When mothers report low depression/anxiety and low negative control, both boys and girls show lower levels of problem behavior and trajectories of disruptive behaviors that decrease over time.

The test of significance for the variance component indicates that there is significant additional variation in the intercept and slope that could be explained by additional person-level variables. To further understand the relations between child sex and the family and mother-child relationship factors and disruptive behavior problems, interaction terms between child sex and the remaining two Level-2 variables were computed and tested. No significant effects were found for the interactions between child sex and maternal depression/anxiety and between child sex and negative control, on developmental trajectories of disruptive behavior. 


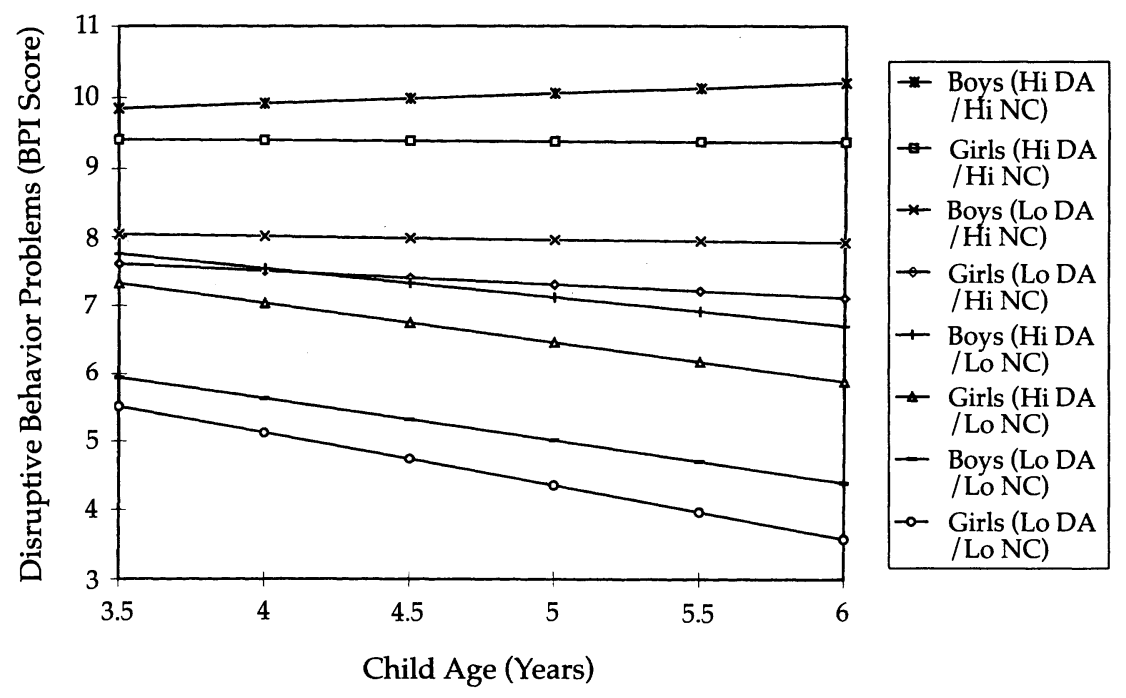

Figure 4 Trajectories of disruptive behavior problems based on combination of maternal depression/anxiety symptoms and maternal negative control, each variable $1 S D$ either above or below the sample mean.

Child race as a moderator. The 69 White and 60 Black children were included in this additional analysis, which is summarized in Table 4 . The model included child sex and child race, maternal negative control, and the race/negative control interaction. Negative control was significant in relation to the intercept and marginally significant, $p=.054$, in relation to the slope, mirroring the results found in the larger sample.

Table 4 Linear Model of Growth in Disruptive Behavior: Prediction from Child Sex, Child Race, Maternal Negative Control, and the Race/Control Interaction

\begin{tabular}{|c|c|c|c|c|}
\hline \multirow[b]{2}{*}{ Level-1 Predictor (Time) } & \multicolumn{4}{|c|}{ Individual Growth Curves } \\
\hline & Variance & $d f$ & $x^{2}$ & $P V^{\mathrm{a}}$ \\
\hline Intercept & 8.59 & 124 & $530.8^{* * *}$ & .382 \\
\hline \multirow[t]{2}{*}{ Slope } & .20 & 124 & $208.6^{* * *}$ & .026 \\
\hline & \multicolumn{4}{|c|}{ Group Growth Curves } \\
\hline Level-2 Predictors & $\beta$ & se & & \\
\hline Intercept & $6.54^{* * *}$ & .72 & & \\
\hline Child sex & .78 & .61 & & \\
\hline Child race & .42 & 1.18 & & \\
\hline Negative control & $.42^{* * *}$ & .06 & & \\
\hline Race/control interaction & $-.20^{*}$ & .08 & & \\
\hline Slope & $-.31^{*}$ & .15 & & \\
\hline Child sex & .15 & .13 & & \\
\hline Child race & .21 & .25 & & \\
\hline Negative control & $.03^{+}$ & .01 & & \\
\hline Race/control interaction & -.02 & .02 & & \\
\hline
\end{tabular}

a Proportion variance explained by Level-2 predictors.

${ }^{+} p<.06 ;{ }^{*} p<.05 ;{ }^{* * *} p<.001$.
Child race was not associated with either the intercept or slope. The interaction term was associated with the intercept, but not the slope. An examination of the correlations between negative control and the BPI disruptive behavior score at each age revealed that the correlations for the White sample were higher at every time-point, $r \mathrm{~s}(64-69)=.42, .63, .51, .49, .68$, .60 from 3.5 to 6.0 years, compared to the Black sample, $r s(57-60)=.30, .48, .45, .48, .43, .41$ from 3.5 to 6.0 years. Scatterplots revealed that the association for Whites was linear across time-points, whereas for Blacks the association was curvilinear, with a leveling off of disruptive behaviors at the higher values of negative control.

The Deater-Deckard and Dodge (1997) hypothesis refers specifically to physical discipline that is harsh but not abusive, whereas in this study, we combined the verbal and physical subscales of the Conflict Tactics Scale (CTS). Mothers of Black children reported significantly higher total CTS scores $(M=14.6, S D=$ $8.4)$, compared to mothers of White children $(M=$ $10.4, S D=6.1), t(127)=-3.24, p=.02$, but not significantly more child disruptive behavior. The two groups of mothers also did not differ in their verbal CTS scores, $t(127)=-1.48, p=.14$, but the mothers of Black children did report higher physical CTS scores $(M=8.1, S D=4.7)$, compared to mothers of White children $(M=5.1, S D=3.1), t(127)=-4.43, p<.001$. The sizes of the correlations between the verbal CTS scores and the BPI disruptive behavior scores are consistently higher for Whites, $r \mathrm{~s}(64-69)=.41-.69$, compared to Blacks, $r s(57-60)=.22-.44$, mirroring the findings for total CTS scores, but there is no consistent 
difference in the size of the correlations between the physical CTS scores and the BPI disruptive behavior scores for Whites, $r s(64-69)=.27-.49$, and Blacks, $r s(57-60)=.33-.49$, despite the much greater range in the physical CTS scores for Blacks.

Deater-Deckard and Dodge (1997) also suggest that the effects of more severe physical punishment are offset by greater maternal warmth. We did not have a measure of maternal warmth with which to compare the two groups of mothers, but we did compare them on symptoms of anxiety/depression, which would be related to lack of warmth and elevated irritability. Overall, the Black mothers reported significantly fewer depression/anxiety symptoms $(M=.58, S D=.41)$, compared to the White mothers $(M=.77, S D=.55), t(127)=2.15, p<.05$.

\section{Teacher Report of Externalizing Problems}

Because all of the variables in the major analyses in this study are derived from maternal report, in the final analysis we asked whether individual differences in mother-reported disruptive behavior growth curves in the preschool years were related to teachers' reports of externalizing problems at age 6.0. In a hierarchical regression analysis predicting the Externalizing T-score on the TRF, each child's BPI disruptive behavior score at the onset of the study, age 3.5, was entered on the first step. This value was unrelated to teachers reports 2.5 years later, $R^{2}=.01, p=.22$. On the second step, each child's BPI slope was entered. When initial BPI disruptive behavior score and slope were in the model at Step 2, both became significant predictors of teacher report, $\beta$ for initial BPI $=.17, p<$ $.05 ; \beta$ for BPI slope $=.31, p<.001 ; \Delta R^{2}=.093, p<$ .001 . The interaction between initial externalizing score and slope, entered on Step 3, did not add to the model. Overall, the model with both initial level of BPI disruptive behavior score and slope of the BPI accounted for $10 \%$ of the variance in teachers reports of externalizing problems at age $6.0, F(2,143)=8.26$, $p<.001$.

\section{DISCUSSION}

This is a study of change in children's disruptive behavior problems across the preschool years. Mothers completed the interviewer-administered BPI checklist every 6 months between 3.5 and 6.0 years. We found that, on average, mothers' reports of disruptive behavior problems decreased across this age range. This finding is in line with other normative work (Campbell, 1995), and suggests that even in a "high risk" sample of children of adolescent mothers, most children are following this same developmental pathway. These data do not tell us, however, if the overall level of disruptive behavior is higher in this sample than would be expected, as there are no norms on the particular set of BPI items used in this study. However, the CBCL (Achenbach, 1991a) was completed by the mothers at the 6-year visit. Results for the CBCL suggest that the level of disruptive behaviors in this sample was elevated compared to CBCL norms. Specifically, more than twice as many children as expected exceeded the borderline clinical cutoff for the normative sample (Achenbach, 1991a), supporting the conclusion that despite the absolute decrease in problem behaviors across the preschool period, many children in this sample were at risk at age 6.0. Because the scores across this age were decreasing on average, we can assume that at least a similar proportion of children would have been in the borderline clinical range at each time point.

Using HLM, we have described the children's changing disruptive behavior problems with two parameters, the intercept (absolute level) and slope (rate of change). HLM permits the examination of personlevel variables to explain the variability in intercept and slope of the sample developmental trajectory. This study examined child, family, and mother-child factors to explain variability in the individual growth curves of disruptive behavior problems across the preschool years.

\section{Sex Differences in Developmental Trajectories}

The child variable was child sex. Consistent with previous work (Keenan \& Shaw, 1997), boys showed a higher absolute level of disruptive behaviors at age 6 . However, boys and girls did not show a significantly different rate of change over the 2.5 years covered by this study. Because, normatively, the absolute level of disruptive behavior does not differ for boys and girls in the toddler years (Keenan \& Shaw, 1997), a difference in slope would be expected to explain the age difference at age 6 . Perhaps a significant difference in the slopes of boys and girls would have been found had the children first been assessed at a younger age, prior to the onset of the divergence in their scores. This conjecture is supported by the finding that the mean BPI scores for boys and girls were significantly different at every data point except at age 3.5 , and the finding that the trajectory for girls declined at a steeper slope, though not significantly so, compared to the trajectory for boys.

It is interesting that the intercept parameter estimate for child sex decreases to nonsignificant when maternal depression/anxiety is also in the model. 
This means that the effect of child sex is mediated, in part, by maternal depression/anxiety symptoms. In this sample, depression/anxiety symptoms, averaged across the six time points, were higher for mothers of boys than for mothers of girls. We do not know why child sex is associated with maternal depression/anxiety symptoms in this particular sample, but depression/anxiety is clearly a more powerful predictor of disruptive behavior problems during the preschool years, accounting for approximately $19 \%$ of the variance beyond that explained by child sex.

\section{Maternal Depression/Anxiety and Child Disruptive Behavior}

The finding that maternal depression/anxiety was associated with the absolute level of disruptive behavior problems is consistent with much of the literature on this topic (Cummings \& Davies, 1994), although not all studies find this association for preschool-age children (Shaw et al., 1996). As in many studies, however, maternal report was the source for both maternal depression/anxiety symptoms and child behavior ratings. The possibility exists that depressed mothers' ratings of child behavior are distorted to report more problems than actually exist (Richters, 1992). Distortion is an issue whenever informants are used. The report of any one informant is always subject to bias from any number of factors, including stress, unemployment, marital conflict, and poor parenting skills (Reid, Kavanagh, \& Baldwin, 1987). Nevertheless, if any one informant has a systematic bias in the perception of a child's behavior problems, that bias poses a problem for the child, regardless of the technical veracity of the rating. Reid et al. found that abusive parents consistently report more disruptive behaviors in their children than the parents of matched control children, despite the fact that direct observations of the two groups of children revealed few differences. On the other hand, the validity of nonabusive parents' reports on behavioral checklists has been established with extensive naturalistic observations (Belsky, Woodworth, \& Crnic, 1996).

In the present study we acknowledge the possibility of bias in maternal reports of child problem behavior, but suggest that the overall pattern of results supports the essential validity of those reports. For example, the slope for maternal depression/anxiety symptoms was unchanged over the preschool years, even as maternal reports of child disruptive behaviors declined. Additionally, although Black mothers reported significantly fewer depression/anxiety symptoms than White mothers, they reported the same level of disruptive behavior problems in their chil- dren. Thus it seems that mothers' reports in this study are based on their children's behavior, and not merely maternal perceptions distorted by concurrent depression/anxiety symptoms.

\section{Maternal Negative Control and Child Disruptive Behavior}

Maternal negative control was associated with both the absolute level of disruptive behavior, as well as change over time. Children whose mothers reported frequent yelling, threatening, and spanking of their children during a conflict or disagreement had children whose disruptive behavior did not decrease over time, as expected at this age and as was observed for the sample as a whole.

The intercept parameter estimate for maternal depression/anxiety decreases, and the proportion of explained variance increases, when maternal negative control is added to the model. Interpreted according to the steps outlined by Baron and Kenny (1986) these results support our hypothesis that the effect of depression/anxiety on child disruptive behaviors would be mediated, in part, by maternal negative control of child behavior, and is in accord with other research that has found similar mediation effects (Campbell et al., 1996; Dodge et al., 1994; Dumas \& Wekerle, 1995; Miller et al., 1993). This was the first study, however, to examine this mediation effect for individual developmental trajectories.

Mothers' negative control was measured at the final two data points, averaged, and used as a Level-2 predictor. These data must be interpreted with caution as to the causal direction of effects. Is maternal negative control contributing to child disruptive behavior problems, or is maternal negative control a response to high and increasing rates of disruptive behavior problems on the part of the children? The answer, based on our findings and the empirical literature, seems to be yes to both alternatives. Although the measurement of maternal negative control occurred at the final two time-points, evidence suggests that this variable was stable. Scores were moderately correlated at the two time-points and there was no difference between the two means. This level of stability is found in other studies. Stattin, Janson, Klackenberg-Larsson, and Magnusson (1995) report that corporal punishment of children is relatively stable, with average year to year correlations being above .50 .

Research also shows that at any point in time, child disruptive behavior and maternal negative control are mutual influences on each other (Campbell et al., 1996). The measure of negative control used in this study is similar to the one used by Campbell and col- 
leagues at age 9. It includes affectively negative verbal tactics like threats, insults, and yells, as well as physical punishment. Campbell et al. found in cross-lagged regression analyses that stability in the mother's negative control is accounted for by stability in the boy's problem behavior. Nevertheless, maternal control at age 4 still predicted to behavior problems at age 9, controlling for stability in behavior problems and later maternal control. Thus, maternal negative control at any point in time may be a response to child behavior, but negative control at earlier times fuels the child's later problem behavior.

The data in this study are compatible with this interpretation, and extend Campbell et al.'s (1996) work by showing that maternal negative control is associated with individual differences in children's disruptive behavior trajectories. Although our data cannot support a causal interpretation, they do support the conclusion that by the end of the preschool years most of the mother-child dyads with high negative control are probably involved in coercive power struggles. The extent to which child behavior is "driving" the process would not change this conclusion.

\section{Does Culture Group Moderate the Effects of Negative Control?}

We examined our data to determine if the interaction between negative control and child race predicted by Deater-Deckard and Dodge (1997) would be observed, and indeed, it was. The significant race by negative control interaction was followed up by analyses which revealed that disruptive behavior problems did not increase linearly for Blacks in relation to maternal negative control, as they did for Whites. The Deater-Deckard hypothesis refers specifically to physical discipline, whereas in this study, we combined physical and verbal conflict tactics. When we examined the data separately by the verbal and physical subscales of the Conflict Tactics Scale (CTS), the pattern of results was as follows: The means for both the total CTS and the physical only CTS scores were higher for mothers of Black children compared to mothers of White children; there was no difference in the level of verbal only CTS scores. However, the correlations between both the verbal only CTS and total CTS scores and the BPI disruptive problem scores were consistently higher over time for mothers of White children compared to mothers of Black children. This pattern suggests two reasons for the finding of a weaker association between negative control (total CTS score) and disruptive behavior problems for Blacks: Maternal report of verbal control tactics is more predictive of disruptive behavior for White chil- dren compared to Black children, and the expected relation between physical control tactics and disruptive behavior problems is attenuated at higher levels of physical control for mothers of Black children. Deater-Deckard and Dodge (1997) discuss several potential explanations for this effect. It may be that the meaning of the various discipline tactics is different for White and Black families, or that the Black mothers employed more positive warmth in conjunction with their greater negative control. Some support for this conjecture comes from the finding that, overall, the Black mothers reported significantly fewer depression/anxiety symptoms, compared to the White mothers. It is possible, therefore, that the Black mothers were warmer and less irritable than the more symptomatic White mothers. In summary, the data in this study support the Deater-Deckard and Dodge hypothesis for the differential effects of physical discipline on the disruptive behavior problems of Black and White children, and extend it to include verbal tactics of maternal negative control. Future research needs to address the processes involved in these cultural group differences.

Finally, maternal negative control also had the same association with preschool-age boys' and girls' trajectories, contrary to the report by McFadyen et al. (1996) in which high maternal control predicted increasing trajectories for boys and decreasing trajectories for girls across the early school years. Future research must address the issue of whether girls show a shift in trajectory in the early school years.

\section{Developmental Trajectories of Disruptive Behavior Problems}

The use of the Externalizing scale of the TRF at age 6.0 provides some corroboration of the mother's report of disruptive behavior problems on the BPI at the same age. The size of the correlation between the two measures, .27, is of the same modest magnitude of association that other researchers have found for concurrent teacher and parent reports (Achenbach, McConaughy, \& Howell, 1987). The romplete lack of association between the 3.5 year mother report of disruptive behavior problems and the 6.0 year teacher report clearly indicates that level of mother-reported problems early in the preschool years alone will not identify children with disruptive problems in their first year of school, a finding that is in accord with other empirical research (Campbell, 1995; Campbell et al., 1996). However, when we combine the mother's report of initial level of disruptive behavior problems with her report of child change in disruptive behavior over time, we can begin to identify which children are 
on developmental pathways, including but not limited to, the "early starter pathway," that will bring their disruptive behavior to the attention of their kindergarten teacher. As the results of this study indicate, we can also begin to identify those child, family, and parent-child factors that are associated with being on problematic pathways. Some of these factors may be most amenable to prevention and intervention efforts if they are targeted early in the preschool years.

Continued improvement in identifying which preschool-age children will persist in the early-starter pathway is needed before intervention efforts can focus on this early period. Growth curve analysis is a promising methodology in this regard. In terms of individual growth curves, early starter children would have high levels of disruptive behavior and a nondecreasing or increasing slope. The children of mothers with high depression/anxiety symptoms and high rates of negative control in this study are described by such a growth curve. Our data suggest that interventions that change parents' negative control strategies could be effective in changing trajectories of disruptive behavior problems during the preschool years.

\section{ACKNOWLEDGMENTS}

The research reported here and the preparation of this report were support by grants from the National Institute of Drug Abuse (DA-05208) and the National Institute of Mental Health (MH-56599) to Lewayne Gilchrist. The authors wish to thank the other members of the research team, the agencies that assisted us in recruiting our sample, and the mothers and children who made the project possible.

\section{ADDRESSES AND AFFILIATIONS}

Corresponding author: Susan J. Spieker, Center for Human Development and Disability, University of Washington, Box 357920, Seattle, WA 98195-7920; e-mail: spieker@u.washington.edu. Nancy C. Larson, Steven M. Lewis, Thomas E. Keller, and Lewayne Gilchrist are also at the University of Washington.

\section{REFERENCES}

Achenbach, T. M. (1991a). Manual for the Child Behavior Checklist/4-18 and 1991 profiles. Burlington, VT: University of Vermont Department of Psychiatry.

Achenbach, T. M. (1991b). Manual for the Teacher's Report Form and 1991 profile. Burlington, VT: University of Vermont Department of Psychiatry.

Achenbach, T. M., \& Edelbrock, C. (1981). Behavioral problems and competencies reported by parents of normal and disturbed children aged four to sixteen. Monographs of the Society for Research in Child Development, 46 (1, Serial No. 188).

Achenbach, T. M., McConaughy, S. H., \& Howell, C. T. (1987). Child/adolescent behavioral and emotional problems: Implications of cross-informant correlations for situational specificity. Psychological Bulletin, 101, 213-232.

American Psychiatric Association. (1994). Diagnostic and statistical manual of mental disorders (4th ed.). Washington, DC: Author.

Baker, P. C., Keck, C. K., Mott, F. L., \& Quinlan, S. V. (1993). NLSY child handbook-Revised edition: A guide to the 19861990 national longitudinal survey of youth child data. Columbus, $\mathrm{OH}$ : The Ohio State University, Ohio Center for Human Resources Research.

Baker, P. C., \& Mott, F. L. (1989). NLSY child handbook 1989. Columbus, $\mathrm{OH}$ : The Ohio State University, Ohio Center for Human Resources Research.

Baron, R. M., \& Kenny, D. A. (1986). The moderator-mediator variable distinction in social psychological research: Conceptual, strategic, and statistical considerations. Journal of Personality and Social Psychology, 51, 1173-1182.

Belsky, J., Woodworth, S., \& Crnic, K. (1996). Troubled family interaction during toddlerhood. Development and Psychopathology, 8, 477-495.

Bryk, A. S., \& Raudenbush, S. W. (1987). Application of hierarchical linear models to assessing change. Psychological Bulletin, 101, 147-158.

Bryk, A. S., \& Raudenbush, S. W. (1992). Hierarchical linear models. Newbury Park, CA: Sage.

Bryk, A. S., Raudenbush, S. W., \& Congdon, R. (1994). Hierarchical linear modeling with the HLM/2L and HLM/3L programs. Chicago: Scientific Software.

Campbell, S. B. (1995). Behavior problems in preschool children: A review of recent research. Journal of Psychology $\mathcal{E}$ Psychiatry \& Allied Disciplines, 36, 113-149.

Campbell, S. B., Pierce, E. W., Moore, G., Marakovitz, S., \& Newby, K. (1996). Boys' externalizing problems at elementary school age: Pathways from early behavior problems, maternal control, and family stress. Development and Psychopathology, 8, 701-719.

Charles Stewart Mott Foundation (1991). A state-by-state look at teenage childbearing in the U.S. Flint, MI: Author.

Compas, B. E., Oppedisano, G., Connor, J. K., Gerhardt, C. A., Hinden, B. R., \& Achenbach, T.M. (1997). Gender differences in depressive symptoms in adolescence: comparison of national samples of clinically referred and nonreferred youths. Journal of Consulting and Clinical Psychology, $65,617-626$.

Cummings, E. M., \& Davies, P. T. (1994). Maternal depression and child development. Journal of Child Psychology and Psychiatry, 35, 73-112.

$\rightarrow$ Deater-Deckard, K., \& Dodge, K. A. (1997). Externalizing behavior problems and discipline revisited: Nonlinear effects and variation by culture, context, and gender. Psychological Inquiry, 8, 161-175.

Derogatis, L. R. (1994). SCL-90-R administration, scoring and procedures manual. Minneapolis, MN: National Computer Systems.

Dishion, T. J., French, D. C., \& Patterson, G. R. (1995). The 
development and ecology of antisocial behavior. In D. Cicchetti \& D. J. Cohen (Eds.), Developmental psychopathology (Vol. 2, pp. 421-471). New York: John Wiley \& Sons.

Dodge, K. A., Pettit, G. S., \& Bates, J. E. (1994). Socialization mediators of the relations between socioeconomic status and child conduct problems. Child Development, 65, 649665.

Dumas, J. E., \& Wekerle, C. (1995). Maternal reports of child behavior problems and personal distress as predictors of dysfunctional parenting. Development and Psychopathology, 7, 465-480.

Downey, G., \& Coyne, J. C. (1990). Children of depressed parents: An integrative review. Psychological Bulletin, 108, 50-76.

Eme, R. F., \& Kavanaugh, L. (1995). Sex differences in conduct disorder. Journal of Clinical Child Psychology, 24, 406426.

Gelfand, D. M., \& Teti, D. M. (1990). The effects of maternal depression on children. Clinical Psychology Review, 10, 329-353.

Ghodsian, M., Zajicek, E., \& Wolkind, S. (1984). A longitudinal study of maternal depression and child behavior problems. Journal of Child Psychology $\mathcal{E}$ Psychiatry $\mathcal{E}$ Allied Disciplines, 25, 91-109.

Gilchrist, L. D., Gillmore, M. R., \& Lohr, M. J. (1990). Drug use among pregnant adolescents. Journal of Consulting and Clinical Psychology, 58, 402-407.

Greenberg, M., Speltz, M. L., \& DeKlyen, M. (1993). The role of attachment in the early development of disruptive behavior problems. Development and Psychopathology, 5, 191-213.

Keenan, K., \& Shaw, D. (1997). Developmental and social influences on young girls' early problem behavior. Psychological Bulletin, 121, 95-113.

McFadyen-Ketchum, S. A., Bates, J. E., Dodge, K. A., \& Pettit, G. S. (1996). Patterns of change in early childhood aggressive-disruptive behavior: Gender differences in predictions from early coercive and affectionate mother-child interactions. Child Development, 67, 2417-2433.

McMahon, R. J. (1994). Diagnosis, assessment, and treatment of externalizing problems in children: The role of longitudinal data. Special Section: Childhood psychopathology. Journal of Consulting and Clinical Psychology, 62, 901-917.

Michels, S., Pianta, R. C., \& Reeve, R. E. (1993). Parent selfreports of discipline practices and child acting-out behaviors in kindergarten. Early Education and Development, 4, 139-144.

Miller, N. B., Cowan, P. A., Cowan, C. P., Hetherington, E. M., \& Clingempeel, W. G. (1993). Externalizing behavior in preschoolers and early adolescents: A cross-study replication of a family model. Developmental Psychology, 29, 3-18.

Patterson, G. R., Capaldi, D., \& Bank, L. (1991). An early starter model for predicting delinquency. In D. Pepler \& K. Rubin (Eds.), The development and treatment of childhood aggression (pp. 139-168). Hillsdale, NJ: Erlbaum.
Reid, J. B., Kavanagh, K., \& Baldwin, D. V. (1987). Abusive parents' perceptions of child problem behaviors: An example of parental bias. Journal of Abnormal Child Psychology, 15, 457-466.

Richters, J. E. (1992). Depressed mothers as informants about their children: A critical review of the evidence for distortion. Psychological Bulletin, 112, 485-499.

Seattle-King County Department of Public Health, Epidemiology Planning and Evaluation Unit. (1996). [Washington State Department of Health, Center for Health Statistics] Unpublished raw data.

Shaw, D. S., Owens, E. B., Vondra, J. I., \& Keenan, K. (1996). Early risk factors and pathways in the development of early disruptive behavior problems. Development and Psychopathology, 8, 679-699.

Shaw, D. S., Vondra, J. I., Hommerding, K. D., Keenan, K., \& Dunn, M. (1994). Chronic family adversity and early child behavior problems: A longitudinal study of low income families. Journal of Child Psychology \& Psychiatry $\mathcal{E}$ Allied Disciplines, 35, 1109-1122.

Spieker, S. J., Larson, N. C., Lewis, S. M., White, R. D., \& Gilchrist, L . (1997). Children of adolescent mothers: Cognitive and behavioral status at age six. Child and Adolescent Social Work Journal, 14, 335-364.

Stattin, H., Janson, H., Klackenberg-Larsson, I., \& Magnusson, D. (1995). Corporal punishment in everyday life: an intergenerational perspective. In J. McCord (Ed.), Coercion and punishment in long-term perspectives (pp. 315-347) New York: Cambridge University Press.

Straus, M. A. (1974). Leveling, civility and violence in the family. Journal of Marriage $\mathcal{E}$ the Family, 36, 13-29, plus Addendum, 442-445.

Teti, D. M., Gelfand, D. M., Messinger, D. S., \& Isabella, R. (1995). Maternal depression and the quality of early attachment: An examination of infants, preschoolers, and their mothers. Developmental Psychology, 31, 364-376.

Vissing, Y. M., Straus, M. A., Gelles, R. J., \& Harrop, J. W. (1991). Verbal aggression by parents and psychosocial problems of children. Child Abuse and Neglect, 15, 223-238.

Webster-Stratton, C. (1996). Early-onset conduct problems: Does gender make a difference? Journal of Consulting and Clinical Psychology, 64, 540-551.

Webster-Stratton, C., \& Hammond, M. (1988). Maternal depression and its relationships to life stress, perceptions of child behavior problems, parenting behaviors, and child conduct problems. Journal of Abnormal Child Psychology, 16, 299-315.

Wilhelm, K., \& Hadzi-Pavlovic, D. (1997). Fifteen years on: Evolving ideas in researching sex differences in depression. Psychological Medicine, 27, 875-883.

Zahn-Waxler, C. (1993). Warriors and worriers: Gender and psychopathology. Development and Psychopathology, 5, 79-90.

Zahn-Waxler, C., Iannotti, R. J., Cummings, E. M., \& Denham, S. (1990). Antecedents of problem behaviors in children of depressed mothers. Development and Psychopathology, 2, 271-291.

Zoccolillo, M. (1993). Gender and the development of conduct disorder. Development and Psychopathology, 5, 65-78. 